\title{
Article \\ Mutations in GDAP1 Influence Structure and Function of the Trans-Golgi Network
}

\author{
Katarzyna Binięda ${ }^{1}$, Weronika Rzepnikowska ${ }^{1}$, Damian Kolakowski ${ }^{2}{ }^{\circledR}$, Joanna Kaminska ${ }^{2}{ }^{\oplus}$, Andrzej \\ Antoni Szczepankiewicz ${ }^{3}$, Hanna Nieznańska ${ }^{3}$, Andrzej Kochański ${ }^{1}$ and Dagmara Kabzińska ${ }^{1, *}$ (1) \\ 1 Neuromuscular Unit, Mossakowski Medical Research Centre, Polish Academy of Sciences, \\ 02-106 Warsaw, Poland; kbinieda@imdik.pan.pl (K.B.); wrzepnikowska@imdik.pan.pl (W.R.); \\ akochanski@imdik.pan.pl (A.K.) \\ 2 Institute of Biochemistry and Biophysics, Polish Academy of Sciences, 02-106 Warsaw, Poland; \\ damian.kolakowski@ibb.waw.pl (D.K.); kaminska@ibb.waw.pl (J.K.) \\ 3 Nencki Institute of Experimental Biology, Polish Academy of Sciences, 02-093 Warsaw, Poland; \\ a.szczepankiewicz@nencki.edu.pl (A.A.S.); h.nieznanska@nencki.edu.pl (H.N.) \\ * Correspondence: dagkab@imdik.pan.pl; Tel.: +48-22-668-55-06
}

Citation: Binięda, K.;

Rzepnikowska, W.; Kolakowski, D.;

Kaminska, J.; Szczepankiewicz, A.A.; Nieznańska, H.; Kochański, A.; Kabzińska, D. Mutations in GDAP1 Influence Structure and Function of the Trans-Golgi Network. Int. J. Mol. Sci. 2021, 22, 914. https://doi.org/ 10.3390/ijms22020914

Received: 17 December 2020

Accepted: 14 January 2021

Published: 18 January 2021

Publisher's Note: MDPI stays neutral with regard to jurisdictional claims in published maps and institutional affiliations.

Copyright: (c) 2021 by the authors. Licensee MDPI, Basel, Switzerland. This article is an open access article distributed under the terms and conditions of the Creative Commons Attribution (CC BY) license (https:// creativecommons.org/licenses/by/ $4.0 /)$.
Abstract: Charcot-Marie-Tooth disease (CMT) is a heritable neurodegenerative disease that displays great genetic heterogeneity. The genes and mutations that underlie this heterogeneity have been extensively characterized by molecular genetics. However, the molecular pathogenesis of the vast majority of CMT subtypes remains terra incognita. Any attempts to perform experimental therapy for CMT disease are limited by a lack of understanding of the pathogenesis at a molecular level. In this study, we aim to identify the molecular pathways that are disturbed by mutations in the gene encoding GDAP1 using both yeast and human cell, based models of CMT-GDAP1 disease. We found that some mutations in GDAP1 led to a reduced expression of the GDAP1 protein and resulted in a selective disruption of the Golgi apparatus. These structural alterations are accompanied by functional disturbances within the Golgi. We screened over 1500 drugs that are available on the market using our yeast-based CMT-GDAP1 model. Drugs were identified that had both positive and negative effects on cell phenotypes. To the best of our knowledge, this study is the first report of the Golgi apparatus playing a role in the pathology of CMT disorders. The drugs we identified, using our yeast-based CMT-GDAP1 model, may be further used in translational research.

Keywords: Charcot-Marie-Tooth disease; GDAP1 gene; Golgi apparatus; inflammation; molecular mechanisms; neuropathy; therapy; yeast-based model organism

\section{Introduction}

Charcot-Marie-Tooth disease (CMT) is a heritable neurodegenerative disease that displays extreme genetic heterogeneity. Over the last three decades, more than 100 genes have been identified as being involved in CMT disease. Despite these advances on the molecular genetics front, the molecular pathogenesis of different CMT subtypes remains unexplored. This lack of understanding at the molecular level has contributed to a lack of effective treatments. CMT disease, resulting from mutations within the gene encoding Ganglioside Induced Differentiation Associated Protein 1 (GDAP1; referred to as CMT-GDAP1), especially from recessive ones, is characterized by a relatively severe clinical outcome. Usually, symptoms first appear during early childhood and the disease is associated with progressive muscle weakness and wasting encompassing distal and proximal parts of the upper and lower limbs. Some patients affected with CMT-GDAP1 are wheelchair-bound [1,2]. To date, more than 100 mutations have been identified in GDAP1 from patients exhibiting a CMT phenotype. The vast majority of them are inherited as autosomal recessive traits, however dominant mutations are also described [3].

GDAP1 was first identified in 1999 as one of a series of ten transcripts, the expression of which are highly elevated upon ganglioside-induced differentiation of murine neuronal 
cell lines [4]. In 2002, two independent groups identified mutations in GDAP1 that led to the rare polyneuropathy, CMT disease [5,6]. Over the last 20 years, knowledge relating to the structure and function of GDAP1 has increased significantly. However, many aspects of its role in cell function and, in particular, of the pathogenesis of CMT-associated GDAP1 mutations are still not understood [3,7]. This lack of understanding hampers efforts to develop an efficient therapy. Currently, there is no efficient treatment for CMT-GDAP1 and, furthermore, no single substance has reached clinical or even pre-clinical testing.

GDAP1 is an outer-mitochondrial membrane protein [8,9] with primary sequence homology to members of the glutathione S-transferase (GST) superfamily $[6,10]$. However, its activity as a GST is highly questionable $[9,11,12]$. The GDAP1 protein is involved in many aspects of mitochondrial physiology [3,7]. In addition, a number of studies suggest that GDAP1 with the junctophilin-1 is involved in the regulation of calcium homeostasis in cells [13-15]. It is therefore interesting that heterologous expression of GDAP1 in yeast suppresses the calcium hypersensitivity of a strain that lacks CSG2 gene $(\operatorname{csg} 2 \Delta)$, encoding the protein required for the formation of complex sphingolipids [16]. It was also reported that GDAP1 is targeted to peroxisomes, where it regulates their morphology [17].

Impairment of mitochondrial homeostasis is seen as the major cause of the CMTGDAP1 disease. Phenotypes associated with a GDAP1 mutation include: disruption of mitochondrial fission-fusion events; changes in mitochondrial distribution; impairment of the mitochondrial transmembrane potential; an increase in reactive oxygen species levels; a reduction in glutathione content; and an alteration of mitochondrial bioenergetics [8,18-23]. Additionally, expression of the mutated GDAP1-Gly327Asp and GDAP1-Leu239Phe alleles in yeast cells increases the rate of DNA escape from mitochondria to the nucleus, indicating an abnormality in mitochondrial functioning [16]. Recently, Fernandez-Lizarbe and coworkers have used the GDAP1 knockout (GDAP1 -/-) mouse model to show that inflammation in the spinal cord and sciatic nerve contributes to the pathophysiology of GDAP1-related CMT [24].

The Golgi apparatus (henceforth referred to simply as the Golgi) is a membrane-bound organelle that plays a central role in the trafficking, processing, and sorting of proteins and lipids. It is often located adjacent to the nucleus in vertebrate cells and consists of several flattened cisternae piled on top of each other and aligned in parallel into compact stacks. Tubular membranes interconnect these stacks to form a ribbon-like network. However, in certain unicellular eukaryotes, including the yeast Saccharomyces cerevisiae, the Golgi structures appear as single, isolated cisternae randomly distributed throughout the cytoplasm $[25,26]$. The Golgi is highly polarized; proteins and lipids from the endoplasmic reticulum (ER) are transported to the cis compartment of the Golgi, then exported through medial- to the trans-Golgi. In the trans-Golgi network (TGN), the cargo is separated, sorted and targeted to other cellular structures including the endosomes, lysosomes and plasma membrane or exported outside of the cell [27]. When passing through the Golgi compartments, cargo molecules are modified and processed. Individual sub-compartments of the Golgi stacks contain unique sets of resident proteins, responsible for maintaining the architecture and function of the Golgi and for modification of cargoes [26,27].

To the best of our knowledge, the present work shows for the first time that, in addition to its roles in mitochondrial and peroxisomal function, GDAP1 also influences the structure and probably the functioning of the Golgi. Decreased levels of GDAP1 protein in SH-SY5Y and HeLa cell lines results in changes in the Golgi morphology as observed by transmission electron microscopy (TEM). What is more, the reduction of the native levels of GDAP1 in HeLa cells alters the maturation and localization of the trans-Golgi protein TGN46. In yeast cells, expression of the GDAP1-Leu239Phe gene specifically affects the distribution of trans-Golgi protein Sec7, suggesting changes in the organization of the Golgi network and demonstrating that yeast is a convenient model in which to study CMT-GDAP1.

To further dissect the role of GDAP1 in the cell and especially how it influences Golgi function, we used a yeast GDAP1-model. Firstly, we investigated the mechanism by which the calcium hypersensitivity associated with $\operatorname{csg} 2 \Delta$ strain is suppressed by human GDAP1. 
We have found that GDAP1-mediated suppression of the calcium sensitivity of $\operatorname{csg} 2 \Delta$ does not require ongoing sphingolipid synthesis. This effect is not dependent on normal functioning of the Golgi, as expression of GDAP1-Leu239Phe, which results in alterations to the Golgi network in yeast, is as beneficial as the expression of wild type GDAP1. Secondly, we decided to screen a drugs library for substances that, similarly to GDAP1, suppress the grown defect of $\operatorname{csg} 2 \Delta$ on calcium-containing medium. The drugs that exhibited a suppressive effect suggest that the effects of GDAP1 on cell function are mediated via different pathways. In summary, we have shown that GDAP1 mutations affect the structure and probably the functioning of different molecular pathways that affect the TGN.

\section{Results}

\subsection{GDAP1 Protein Levels Influence Mitochondria and Golgi Morphology in SH-SY5Y Cells}

The molecular function of GDAP1 in cells has not been determined. Here we investigated the effect of altering GDAP1 expression levels (either reduced or overexpressed) in the SH-SY5Y cell line derived from human neuroblastoma. Neuron-derived cells are a suitable model to study GDAP1-associated effects due to the involvement of GDAP1 in the pathogenesis of peripheral neuropathies. To reduce expression of GDAP1, RNA silencing was used. Western blot analysis revealed that, $24 \mathrm{~h}$ after siRNA transfection, the level of GDAP1 was markedly reduced in comparison to the control. This reduction of expression could still be observed, albeit less so, $48 \mathrm{~h}$ post-transfection (Figure 1a).

(a)

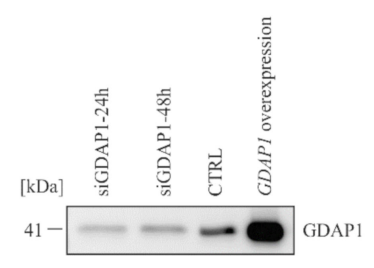

(c)

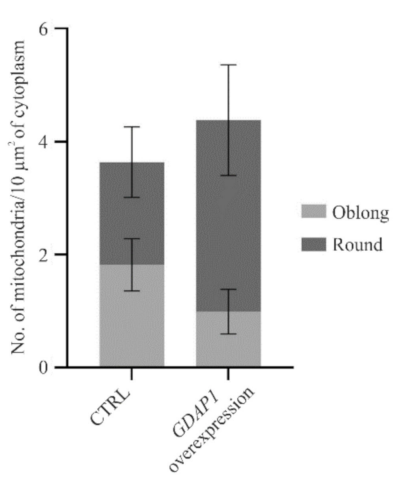

(b)

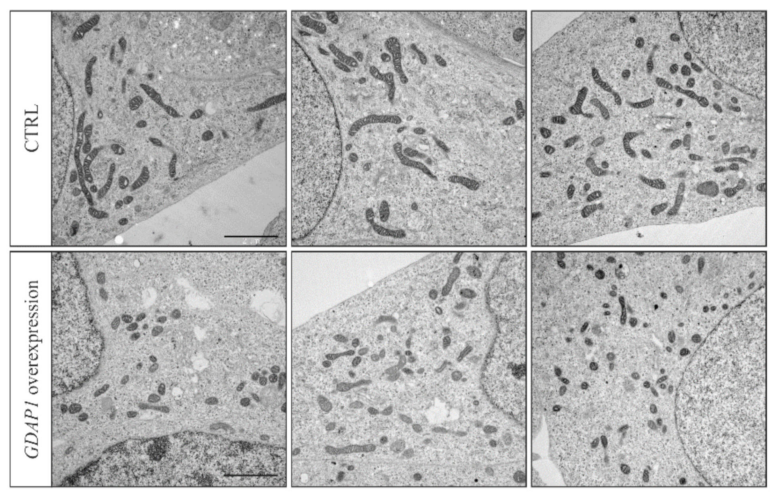

(d)

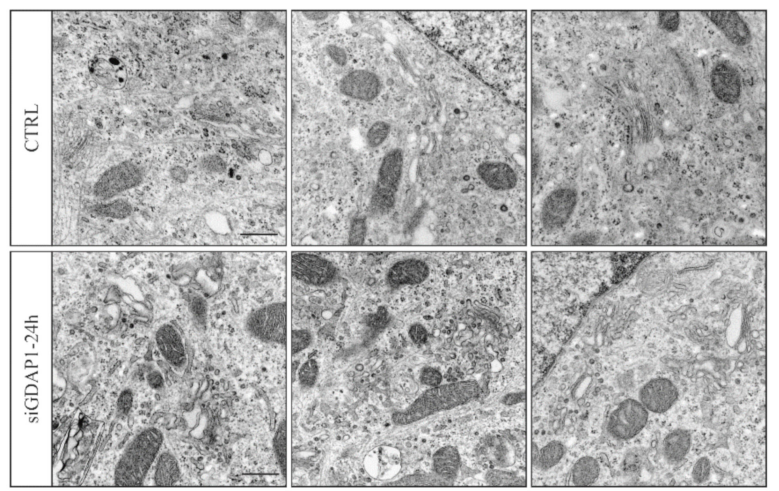

Figure 1. GDAP1 levels in SH-SY5Y cells determines the morphology of mitochondria and the Golgi. (a) The level of GDAP1 following 24 or $48 \mathrm{~h}$ of siRNA silencing, and after GDAP1 overproduction. Western blot analysis of total cell extracts using an anti-GDAP1 antibody. (b) Electron micrographs presented mitochondrial morphology in cells overexpressing GDAP1. Scale bar $2 \mu \mathrm{m}$. (c) Quantification of results from (b). (d) Morphology of the Golgi following GDAP1 gene silencing in SH-SY5Y cells on electron micrographs. Scale bar $500 \mathrm{~nm}$. 
It can also be seen that overexpression of GDAP1 was very effective (Figure 1a). The influence of GDAP1 concentration on the structure of the mitochondria and Golgi was investigated using transmission electron microscopy (TEM).

It was previously shown that GDAP1 is involved in the maintenance of mitochondrial morphology. Thus, we began by analyzing the general appearance of these organelles in cells with altered levels of GDAP1. Figure $1 \mathrm{~b}$ shows that overexpression of GDAP1 affects mitochondrial size and shape: mitochondria were smaller and rounder compared to those in the control cells. This finding is in agreement with previously published data $[8,28]$. The effect of GDAP1 gene silencing on mitochondria was not evident. We cannot discriminate between cells without and with significant GDAP1 silencing (Figure 1a). We were unable to determine GDAP1 levels for individual cells and thus could not associate mitochondrial morphology with a specific GDAP1 concentration. Surprisingly during the examination of the TEM images, we found that even a partial reduction of GDAP1 levels resulted in alterations to Golgi morphology; the cisternae were more irregular in shape and the ends of the stacks are denser (Figure 1d). Thus, TEM analysis of a neuroblastoma cell line suggested that GDAP1 protein may also influence the structure and function of the Golgi.

\subsection{Exogenous Expression of Particular GDAP1 Variants Affects the Endogenous GDAP1 Protein} Levels in HeLa Cells

As the previous experiment pointed to the involvement of GDAP1 in maintenance of the Golgi structure, we hypothesized that the pathogenic effects of GDAP1 mutations may, at least partially, result from a failure of this organelle. To test this hypothesis, we examined the influence of selected GDAP1 variants on Golgi morphology. The SH-SY5Y cell line is characterized by a high expression of endogenous GDAP1, which makes it impossible to observe the effects of recessive GDAP1 gene variants. Thus, for further experiments, we used the HeLa cell line that was previously used to characterize GDAP1 mutants [12,21,29]. Six GDAP1 mutations were analyzed (Figure 2a) based on the following criteria: (i) whether the GDAP1 mutation is inherited as an autosomal recessive (4 alleles) or autosomal dominant trait (3 alleles), (ii) frequency of the mutations (GDAP1-Leu239Phe) in the population (recurrent mutation) and (iii) availability of clinical data for phenotypes of CMT disease associated with a specific mutation. The GDAP1-Pro153Argfs ${ }^{*} 19$ mutation has never been identified in a patient with CMT; it was generated by mutagenesis and was included here to represent the frame-shift, loss of function mutations of GDAP1.

To study the effect of expressing selected GDAP1 alleles in HeLa cells, we initially analyzed the levels of mutant GDAP1 proteins. Surprisingly, it was observed that following transfection with vector only, or with vector bearing wild-type GDAP1 or with specific GDAP1 alleles (namely GDAP1-Pro153Argfs*19, GDAP1-Gln218Glu and GDAP1-Leu239Phe) the total level of GDAP1, including the endogenously expressed protein, dropped markedly (Figure 2b). However, following expression of the GDAP1-Gly327Asp, GDAP1-Glu222Lys and GDAP1-His123Arg alleles, the level of GDAP1 protein increased to a level comparable to that observed for the SH-SY5Y cell line (Figure 2b). Based on this observation, we concluded that GDAP1 variants may be assigned into two groups. The first group displays the same effect observed for expression of wild type GDAP1—silencing of the endogenous GDAP1. The second group includes certain variants, expression of which resulted in the overproduction of GDAP1.

\subsection{A Reduction of GDAP1 Expression Alters Golgi Morphology in HeLa Cells}

Expression of some GDAP1 variants in HeLa cells clearly leads to a reduction of total GDAP1. We checked if, similarly to neuroblastoma cells, a decreased amount of GDAP1 in HeLa cells also resulted in alterations to the Golgi morphology. TEM analysis revealed that intact Golgi were visible in about $20 \%$ of control cells. Approximately $50 \%$ of the control cells exhibited an altered Golgi morphology; one that takes the form of cisternae plus vacuoles (altered type I). The fraction of cells-in which the Golgi in the form of cisternae is invisible-was also recorded (altered type II). In cells expressing the GDAP1-Leu239Phe allele (with a reduced GDAP1 level) the number of cells with distinguishable cisternae (both 
unaltered and altered type I) decreased while the percentage of cells in which the Golgi took the form of vacuoles only (altered type II) increased (Figure 3). The cells expressing GDAP1-Gly327Asp (resulting in overexpression of GDAP1) also exhibited an altered Golgi morphology, but the changes were minor compared to those observed in cells expressing GDAP1-Leu239Phe. Expression of GDAP1-Gly327Asp resulted in a slight increase in the number of cells in which the Golgi took the form of vesicles (Figure 3).

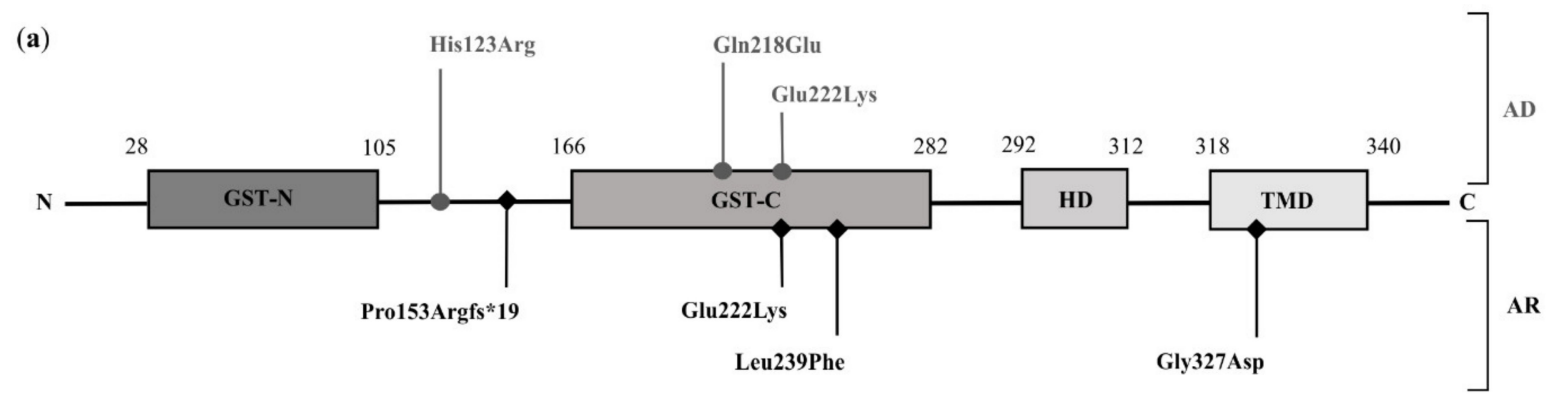

(b)

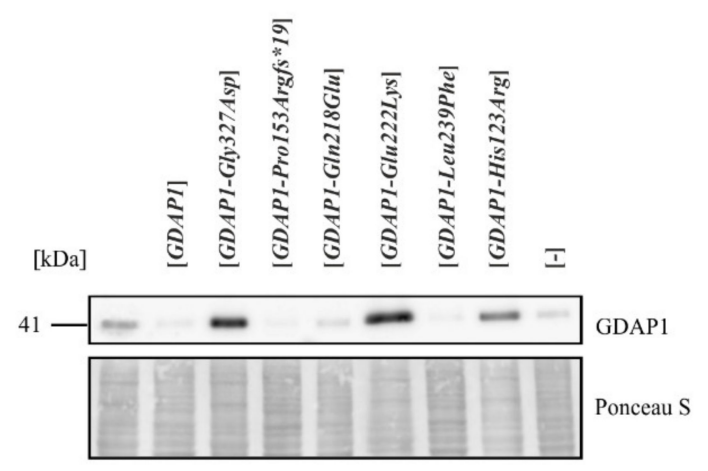

Figure 2. Expression of various GDAP1 alleles in HeLa cells affects the level of endogenous GDAP1. (a) Schematic representation of GDAP1 structure including amino acid residue substitutions that result from the GDAP1 variants of autosomal dominant (AD; above schematic) or autosomal recessive (AR; below schematic) modes of inheritance. (b) Western blot analysis using anti-GDAP1 antibody. Shown are total cell extracts from non-transfected HeLa cells (first lane from left), HeLa cells transfected with empty vector ([-]) or HeLa cells transfected with vectors carrying the indicated GDAP1 variants. The samples were normalized for protein loading using Ponceau S staining.

\subsection{A Reduction of GDAP1 Expression Results in Changes to Post-Translational Modifications of TGN46}

We asked if alterations of the Golgi structure in HeLa cells is also manifested at a molecular level as changes in the levels or modifications of Golgi proteins. Initially we analyzed the levels of Golgi proteins that are characteristic of the cis- and trans-Golgi regions. There were no statistically significant changes in the level of the cis Golgi marker, GM130, but changes in the pattern of bands of the trans-Golgi marker, TGN46, were observed (Figure 4).

TGN46 is a type I transmembrane glycoprotein, which migrates as several bands during electrophoresis. The $>110 \mathrm{kDa}$ form is the mature sialylated protein. Western blot analysis revealed that the expression of some GDAP1 mutant alleles resulted in a drop in the endogenous GDAP1 level, and this correlates with a change to the pattern of posttranslational modification of TGN46. In cells expressing GDAP1, GDAP1-Pro153Argfs ${ }^{*} 19$, GDAP1-Gln218Glu and GDAP1-Leu239Phe, TGN46 did not fully mature; the slower migrating forms, shown previously to be sialylated forms, were absent. A $70 \mathrm{kDa}$ form was more pronounced in the cells expressing the mutant alleles (Figure 4). Thus, a reduction in GDAP1 levels alters some processes carried out in the Golgi, reflected by changes in TGN46 maturation. 


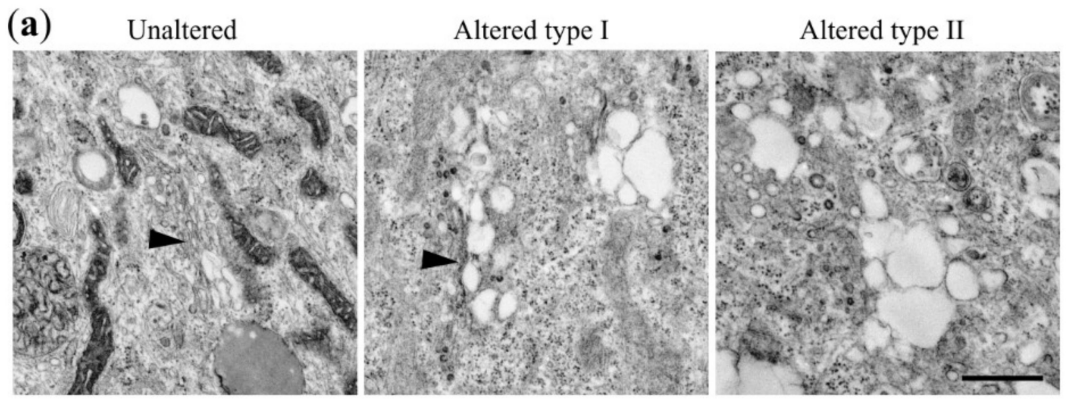

(b)

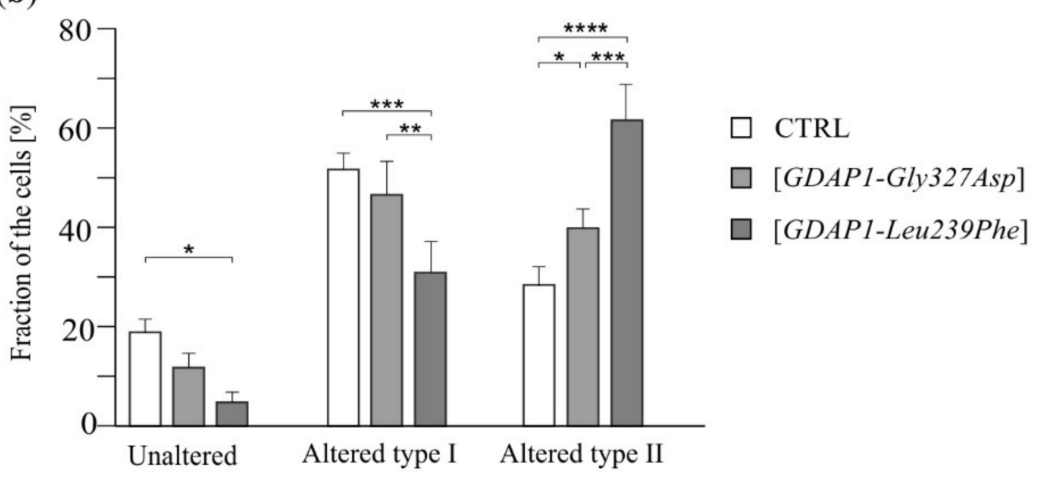

Figure 3. Expression of mutant GDAP1 variants affects the morphology of the Golgi in HeLa cells. (a) Transmission electron microscope analysis of the Golgi in non-transfected HeLa cells (CTRL) or in HeLa cells transfected with a vector carrying GDAP1-Gly327Asp or GDAP1-Leu239Phe alleles. Electron micrographs of representative examples of Golgi structures observed in HeLa cells. Black arrowheads indicate the cisternae of the Golgi. Scale bar $750 \mathrm{~nm}$. (b) Fraction of cells [as percentage of counted cells] with types of Golgi ultrastructure indicated. Statistical analysis was performed on data from three independent experiments using one-way ANOVA and Bonferroni's correction: ${ }^{*} p<0.05,{ }^{* *} p<0.01,{ }^{* * *} p<0.001,{ }^{* * * *} p<0.0001$.

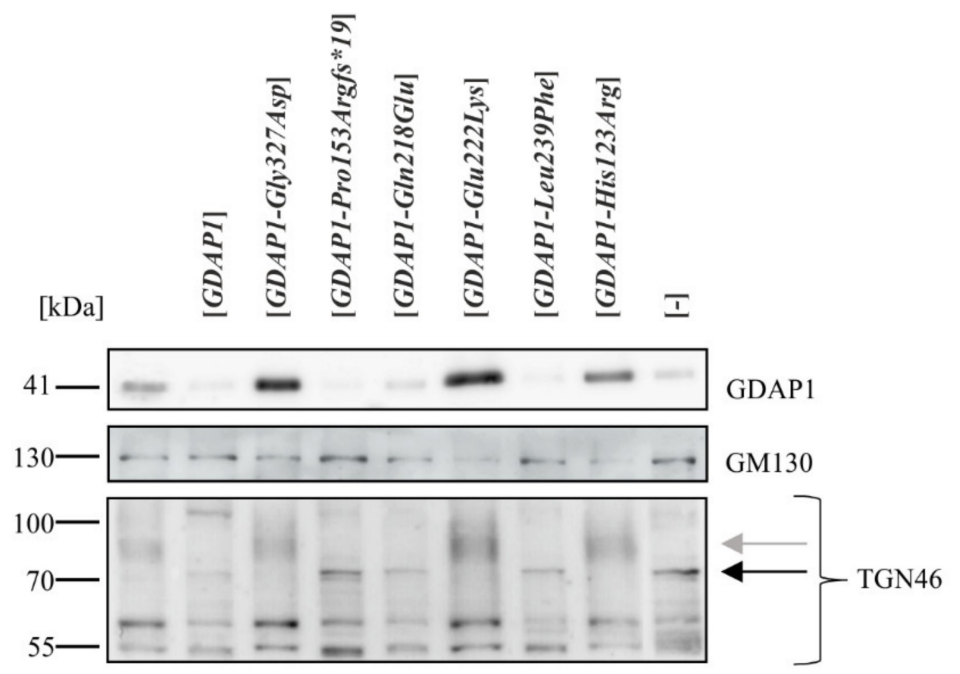

Figure 4. The level of GDAP1 protein correlates with changes in the pattern of TGN46 modifications. Western blot analysis of total cell extracts from not transfected HeLa cells (far left lane), transfected with empty vector ([-]) or vectors bearing variants of GDAP1 (as indicated). Western blots performed using antibodies against GDAP1 or against the Golgi proteins GM130 and TGN46. The black arrow indicates immature TGN46, the grey arrow shows mature, modified forms. 


\subsection{Localization of TGN46 Is Altered in HeLa Cells Expressing the GDAP1-Leu239Phe Variant}

Post-translational modification of proteins regulates their activity, stability and localization. As discussed above, HeLa cells with a reduced level of GDAP1 exhibited alterations in expression and maturation of TGN46. We therefore decided to test if these alterations also affected the localization of TGN46 in cells with expression of two chosen mutant alleles as the representatives of two different GDAP1 expression level. These mutations are the most common one, GDAP1-Leu239Phe, and GDAP1-Gly327Asp, which results in disturbing GDAP1 targeting to the mitochondrial membrane [2,30]. In order to visualize the morphology of the Golgi we immunostained the GM130, GORASP2 and B4GALT3 proteins. All proteins were observed using confocal microscopy. In the control HeLa cells, GM130 ( cis-Golgi marker), GORASP2 (medial-Golgi), B4GALT3 (TGN) and TGN46 (TGN), were present in structures near one pole of the nucleus, as expected for Golgi proteins. A similar localization of these proteins was observed for cells expressing the GDAP1-Gly327Asp allele. In contrast, in cells expressing GDAP1-Leu239Phe, the distribution of TGN46 was altered; it was localized in tubular structures (Figure 5). This mislocalization of TGN46 could arise as a consequence of altered post-translational modification or, conversely, the mislocalization could be responsible for alterations in post-translational modification of TGN46.

2.6. Yeast Cells Transformed with the GDAP1-Leu239Phe Gene Allele Exhibit Changes in the Localization of $\mathrm{Sec} 7$

Recently, we have demonstrated that it is possible to determine the effects of GDAP1 expression on yeast cell physiology. In addition we showed that expression of different GDAP1 alleles may have different effects on the functioning of yeast cells [16]. We hypothesized that the effects of a GDAP1 variant on the Golgi were similar for both the HeLa and yeast cell models. Thus, we decided to check if expression of the same GDAP1 alleles as in HeLa cells: GDAP1, GDAP1-Gly327Asp and GDAP1-Leu239Phe could alter the localization of Golgi proteins in yeast cells. In order to compare models, we monitored two different Golgi marker proteins, Sed5 and Sec7, tagged with red fluorescence protein (mRFP). Sed5 is a cis-Golgi marker while Sec7 serves as a TGN marker [31]. In yeast cells, the Golgi structure differs from the classical cisternae stacks observed in mammalian cells. Yeast Golgi takes the form of dispersed cisternae throughout the cytoplasm, observed as single puncta. Confocal microscopy revealed that the number of Sed5-mRFP spots was similar in all examined transformants (Figure S1). In contrast, cells expressing GDAP1-Leu239Phe had a higher number of Sec7-mRFP containing puncta (Figure 6). This suggests that the yeast trans-Golgi could also be affected by expression of GDAP1-Leu239Phe. As the phenotypes observed in HeLa cells are similar to those observed for yeast cells, it raises the possibility that yeast cells could be used to further investigate the influence of GDAP1 variants on Golgi structure and function.

\subsection{GDAP1-Mediated Suppression of the Calcium Sensitivity of $\operatorname{csg} 2 \Delta$ Does Not Require Ongoing Sphingolipid Synthesis}

The effect of GDAP1 gene expression on yeast cell physiology is apparent when it is expressed in a $\operatorname{csg} 2 \Delta$ mutant. This expression results in suppression of the calcium sensitivity of the $\operatorname{csg} 2 \Delta$ mutant and different GDAP1 variants either retain or lose this suppressive ability [16]. Csg2 is a Golgi localized protein, which is required for mannosylation of inositolphosphorylceramide i.e., the formation of complex sphingolipids (Figure 7a).

It was shown that Csg2 is also required for the efficient retention of some medialGolgi enzymes [32]. To uncover the molecular mechanisms underlying GDAP1-mediated suppression of calcium sensitivity in a $\operatorname{csg} 2 \Delta$ mutant, and to test if the observed effect is Golgi-dependent, we asked if ongoing sphingolipid synthesis is necessary for the efficiency of GDAP1-mediated suppression. Furthermore, we asked if the GDAP1-Leu239Phe variant, which affects trans-Golgi protein localization in yeast, improves the growth of the $\operatorname{csg} 2 \Delta$ mutant in the presence of calcium ions. We examined if the addition of myriocin, which blocks the first enzyme of the sphingolipid synthesis pathway, abolishes GDAP1-mediated 
suppression. To answer these questions the growth of the $\operatorname{csg} 2 \Delta$ mutant on plates containing calcium ions was compared to growth on plates containing calcium ions and myriocin. The growth of $\operatorname{csg} 2 \Delta$ was reduced by the addition of calcium ions and further by the addition of myriocin. When $\operatorname{csg} 2 \triangle$ was transformed with GDAP1 or the GDAP1-Leu239Phe allele, it grew better than when transformed with an empty plasmid or with the GDAP1-Gly327Asp allele (Figure $7 \mathrm{~b}$ ). This suggests that the presence of GDAP1 protein reduces the toxicity of calcium ions in a $\operatorname{csg} 2 \Delta$ mutant in a manner that does not involve ongoing sphingolipid biosynthesis. Furthermore, this suggests that the GDAP1-based suppression is not related to the effects of the GDAP1 protein on the Golgi; the expression of GDAP1-Leu239Phe, which changes the modification and localization of TGN46 in HeLa cells and number of Sec7-mRFP containing structures in yeast cells, has a positive effect on the growth of the $\operatorname{csg} 2 \Delta$ mutant, which already has an altered Golgi apparatus.

HeLa
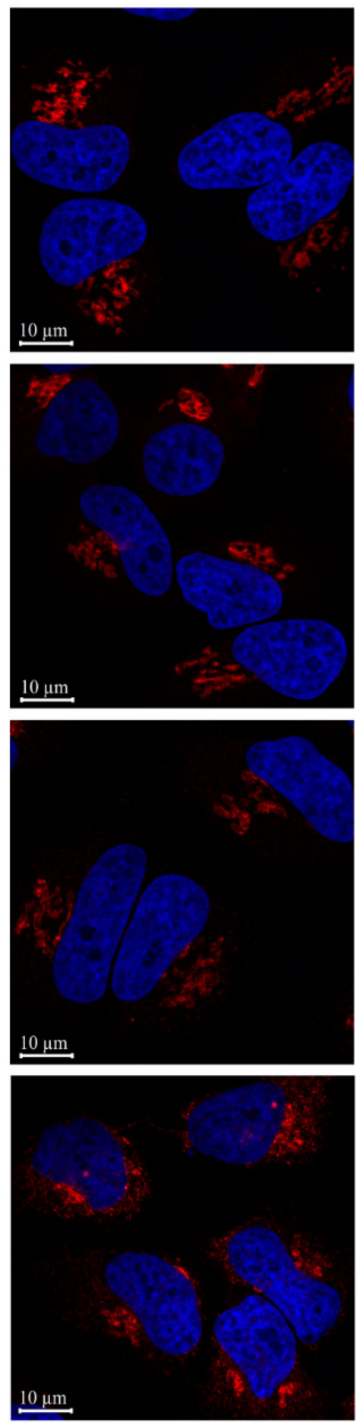

HeLa

GDAP1-Gly327Asp

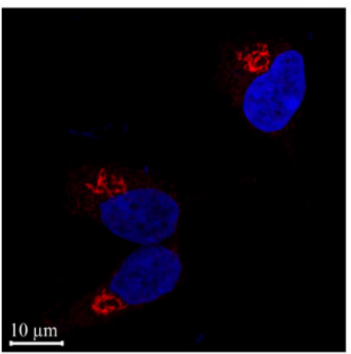

HeLa

GDAP1-Leu239Phe

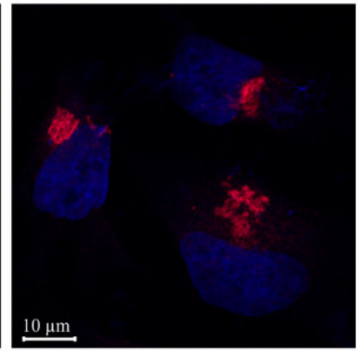

GM130

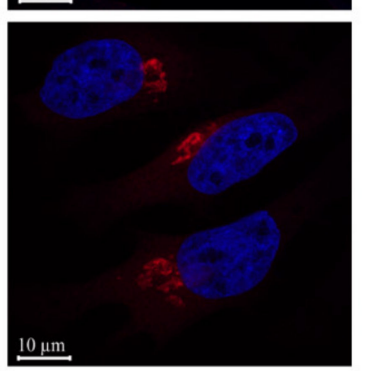

GORASP2
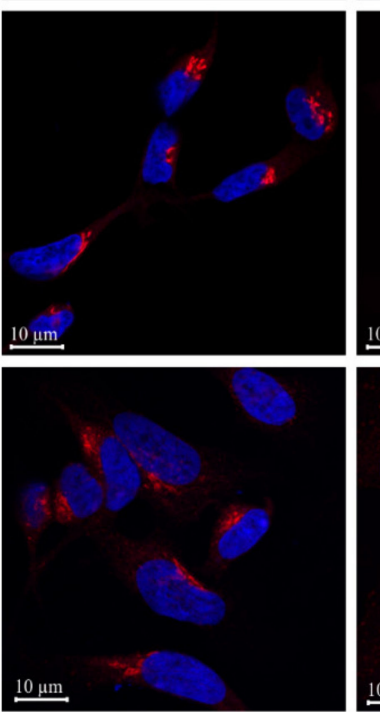

B4GALT3
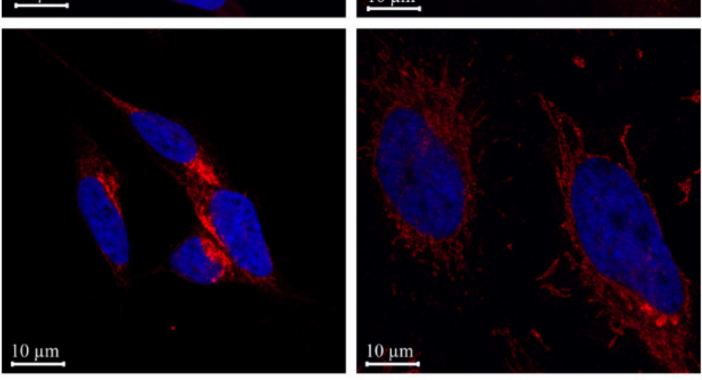

Figure 5. The localization of TGN46, a protein of the trans-Golgi network, is altered in HeLa cells expressing the GDAP1Leu239Phe allele. The confocal microscopy images show the localization of GM130, GORASP2, B4GALT3 and TGN46 proteins in the control HeLa cells or in HeLa cells expressing the GDAP1-Gly327Asp or GDAP1-Leu239Phe alleles. All proteins were visualized by indirect immunofluorescence. Nuclear DNA was stained with DAPI. 


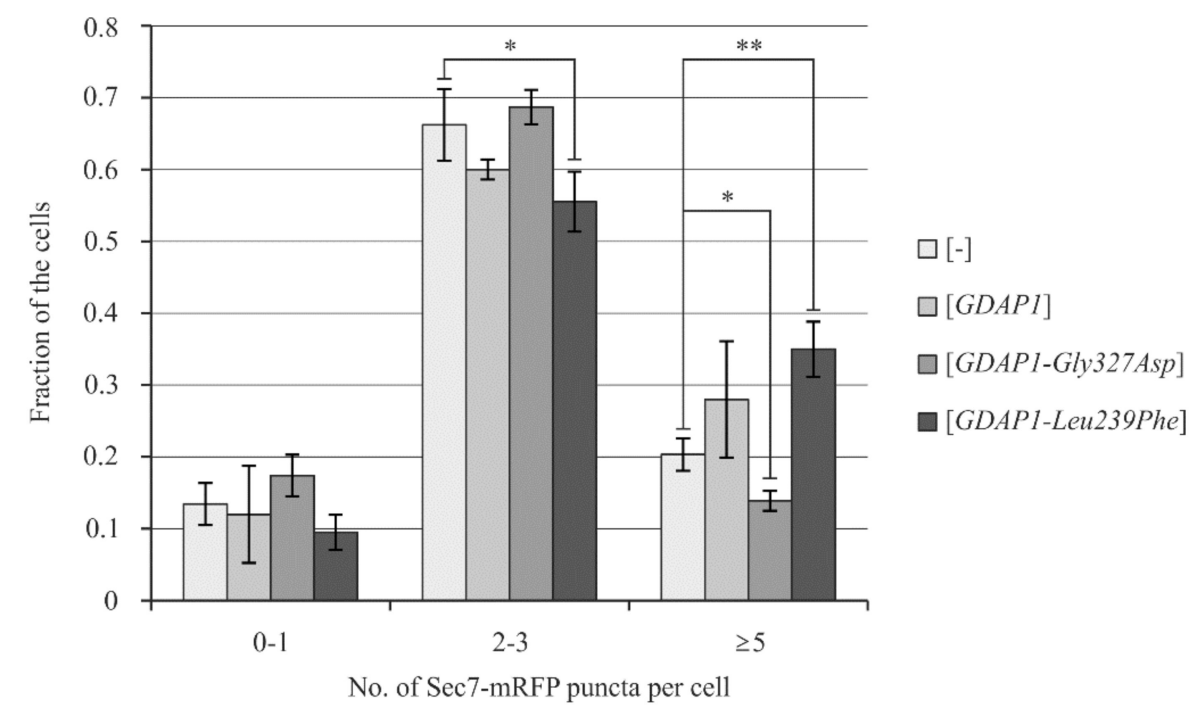

Figure 6. The expression of GDAP1 variants in yeast cells influences localization of Sec7-mRFP, the transGolgi network marker protein. Yeast cells carrying the SEC7-mRFP-containing plasmid were observed using confocal microscopy. The number of Sec7-mRFP puncta in a single cell was determined. Error bars represent standard deviation for three repeats. Statistical analysis was performed on data from three independent experiments using t-Test. * $p$-value $<0.05 * * p$-value $<0.01$.

(a)

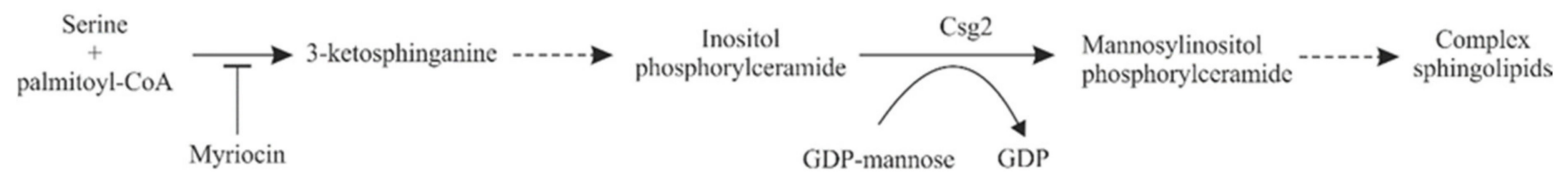

(b)

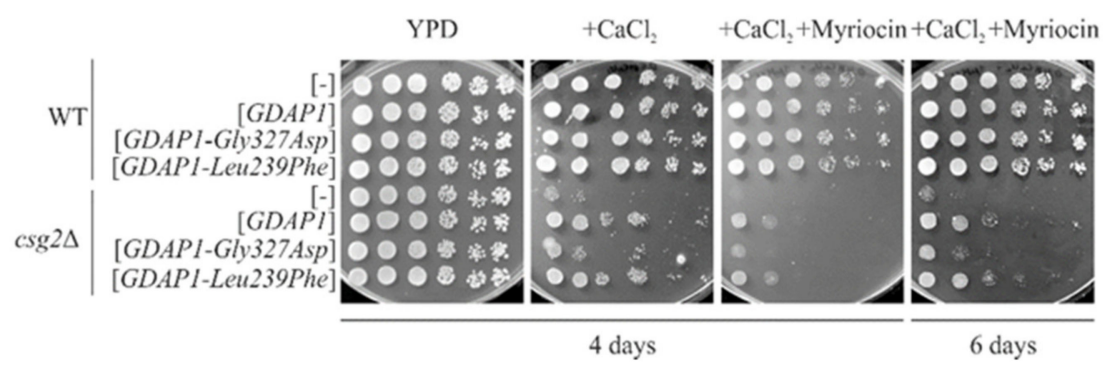

Figure 7. Expression of GDAP1 or the GDAP-Leu239Phe allele suppresses the sensitivity of the $\operatorname{csg} 2 \Delta$ mutant to Ca ${ }^{2+}$ ions even in the presence of myriocin. (a) Schematic representation of the sphingolipid biosynthesis pathway. The step inhibited by myriocin is indicated. (GDP) guanosine diphosphate. (b) The growth of wild-type and $\operatorname{csg} 2 \triangle$ mutant strains transformed with empty vector ([-]), or vectors carrying the cDNA of GDAP1, ([GDAP1]) or GDAP1 variants ([GDAP1-Gly327Asp] and [GDAP1-Leu239Phe]) was compared on YPD media or YPD containing $0.4 \mathrm{M}$ calcium chloride $\left(+\mathrm{CaCl}_{2}\right)$ or $0.4 \mathrm{M} \mathrm{CaCl}_{2}$ and $1 \mu \mathrm{M}$ myriocin $\left(+\mathrm{CaCl}_{2}+\right.$ Myriocin).

2.8. Screening a Drug Library Using the Calcium Hypersensitivity of the csg2 $\Delta$ Strain Revealed Ibuprofen Piconol as an Active Compound

We have already ruled out the influence of GDAP1 protein on the sphingolipid biosynthesis pathway and related GDAP1's effects to changes in the structure of the Golgi. The molecular mechanism by which GDAP1 acts in $\operatorname{csg} 2 \Delta$ cells is still unknown. For a further dissection of the GDAP1-dependent suppression of calcium hypersensitivity in 
a $\operatorname{csg} 2 \Delta$ mutant, we used a chemical suppressor screen, assuming that we would find a compound that exerts an effect similar to that caused by the expression of GDAP1. Identification of such a compound, coupled with its mechanism of action, will be used to determine the role of GDAP1. We adapted the $\mathrm{Ca}^{2+}$ ion sensitivity phenotype of a $\operatorname{csg} 2 \Delta$ mutant for use in a drug screen (Figure 8 ), in order to identify molecules that suppress the calcium hypersensitivity associated with $\operatorname{csg} 2 \Delta$. We screened the Prestwick drug repurposing library (Prestwick Chemical Library) previously used in such screens [33-35], which contains drugs approved for use in humans.

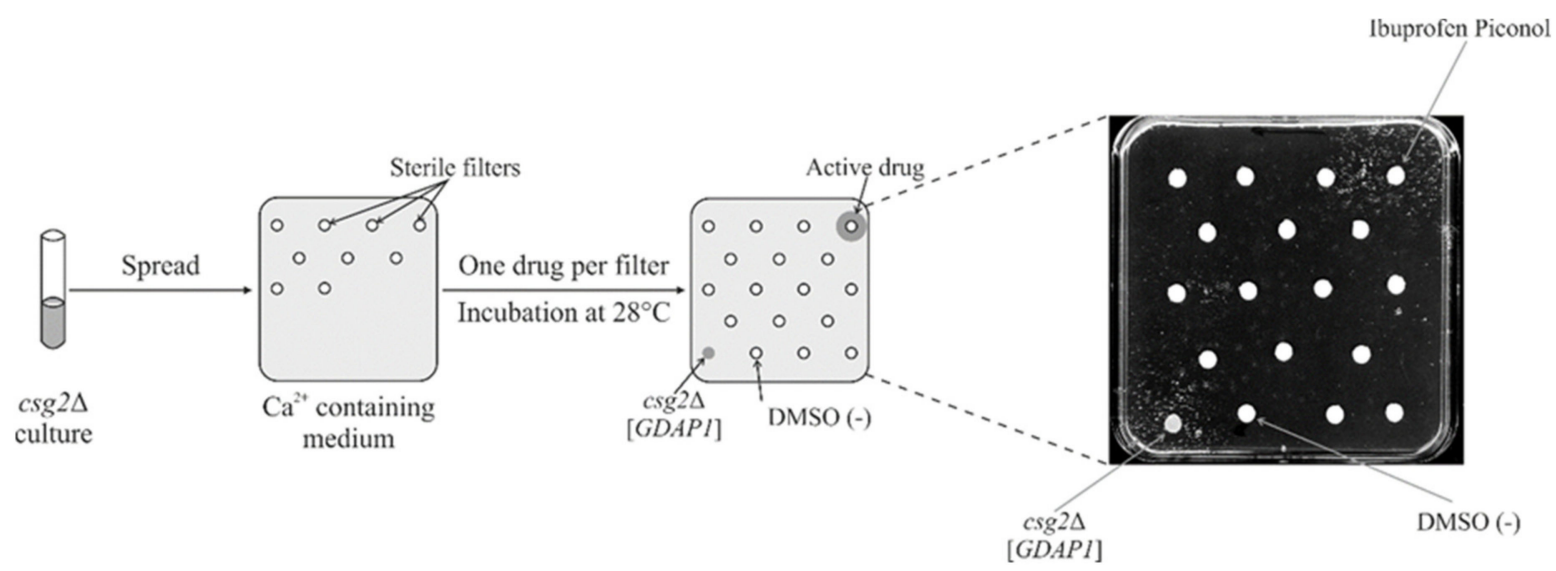

Figure 8. Ibuprofen piconol is a chemical suppressor of the $\operatorname{csg} 2 \Delta$ growth defect on media supplemented with $\mathrm{Ca}^{2+}$ ions. The $\operatorname{csg} 2 \Delta$ cells were plated on YPD $+0.5 \mathrm{M} \mathrm{CaCl}_{2}$. Compounds from the Prestwick library were applied on filter discs $(2 \mu \mathrm{L}$ of $10 \mathrm{mM}$ solution in DMSO). DMSO, a solvent, was used as a negative control. The $\operatorname{csg} 2 \Delta$ [GDAP1] strain was spotted as a positive control. Plates were incubated for $3-5$ days at $28{ }^{\circ} \mathrm{C}$.

Library compounds were applied to filter discs on top of solid media. Active compounds were identified after 3-5 days by observation of growth zones around the filter. Two drugs were identified as suppressors of the $\operatorname{csg} 2 \Delta$ growth defect on $\mathrm{Ca}^{2+}$ ion containing media. The first was a previously identified chemical suppressor: cyclosporine A. The second was ibuprofen piconol (Figure 8), a nonsteroidal anti-inflammatory agent that inhibits synthesis of prostaglandins in mammalian cells, but is also regarded as a phospholipase inhibitor. In summary, expression of GDAP1 suppresses $\operatorname{csg} 2 \Delta$, not through biosynthesis of sphingolipids, but via another conserved pathway, most probably connected with calcium homeostasis, inhibition of phospholipase A or both.

\section{Discussion}

Although almost 20 years have passed since GDAP1-associated CMT disease was first described, its molecular pathogenesis is still not understood. The molecular pathogenesis of CMT-GDAP1 disease has been linked to a mitochondrial pathology and to disturbances in calcium homeostasis. The uncertainty as to the underlying causes of the pathogenesis mean that even experimental therapies are not possible. Clinical trials for the treatment of patients suffering from other types of CMT have been conducted and published, which suggests a road map for the future [36,37]. The main issue here is the diversity of phenotypes caused by different mutations in GDAP1. In the present study, we have shown two additional molecular phenotypes associated with mutations in GDAP1. Here we analyzed six mutations in GDAP1, three resulted in lower levels of GDAP1, and the other three did not. In addition, the mutations that influence GDAP1 levels, such as GDAP1-Leu239Phe, also affected the morphology of the Golgi. These alterations in morphology are visualized as a conversion of Golgi structures (from cisternae to vesicles) as detected by TEM in neuroblastoma as well as in HeLa cells. These changes are accompanied by changes in the modification and localization of TGN46, a protein of the TGN. The impact of GDAP1 on the Golgi was also apparent in yeast cells expressing GDAP1-Leu239Phe. We then used yeast 
model to screen for drugs that could restore normal functioning in the absence of GDAP1. To the best of our knowledge, this study is the first report of a link between disturbances in the Golgi and the molecular pathogenesis of Charcot-Marie-Tooth disorders.

Initial studies suggested that GDAP1 expression was limited to the neural cell lines. Later studies suggested that this is not the case: human fibroblasts contain about $2.6 \%$ GDAP1 mRNA levels found in motor neurons and at least some GDAP1 mutations result in a dramatic reduction of GDAP1 mRNA expression in CMT patients fibroblasts [20]. Interestingly, the same effect, the very low levels of GDAP1, is observed in the fibroblasts of patients carrying the homozygous GDAP1-Leu239Phe and GDAP1-Arg273Gly mutations [20] and in HeLa cells transfected with a plasmid expressing the GDAP1-Leu239Phe variant. This similarity between the molecular effects of the GDAP1-Leu239Phe mutation in two divergent cell lines (fibroblasts biopsied taken from patient and HeLa cells) supports our use of HeLa cells in these studies. Thus, mutations that reduce GDAP1 levels have a similar effect to loss of function mutations or even knockout mutations. It is interesting to establish how the level of GDAP1 correlates with the severity of clinical manifestation. At least in other CMT type diseases caused by mutations in the IGHMBP2 gene, there is a correlation between the IGHMBP2 level and severity of the disease [38].

The TGN is a particularly dynamic structure: microscopic observations show the continuous formation of tubules and vesicles in this part of the Golgi. This process requires tubulin dimers. Tubules appear to be drawn from the TGN along the microtubules. Once formed, the vesicular tubular carriers move towards the periphery of the cell, transported along the microtubules [39]. It is proposed that the defects in microtubule-dependent trafficking lead to neurodevelopmental and neurodegenerative diseases including Alzheimer's disease, Parkinson's disease, amyotrophic lateral sclerosis (ALS; also known as Motor Neurone Disease or Lou Gehrig Disease) or traumatic brain injury. Recent studies highlight the use of microtubule stabilizing agents as potential drugs for improving axonal transport and therefore nerve function in these diseases [40]. Noteworthy, the pathogenesis of CMT2Z caused by mutations in MORC2 gene could be also linked to disturbances in trafficking along microtubules [41]. Beta-tubulin is known to interact with GDAP1 [14,15], therefore changes in the interaction between beta-tubulin and GDAP1, caused by mutations in GDAP1, could impact microtubules and subsequently TGN structure and function. However, the changes caused by mutations in GDAP1 are subtle and impact only the TGN. In contrast, for Alzheimer's disease, Parkinson's disease and ALS, fragmentation of the whole Golgi has been reported [42]. The number of reports showing fragmentation of the Golgi limited to the TGN is scarce. In HEK293 cells expressing Rab71 and in a LRRK2 mutant (a model for Parkinson's disease), Golgi fragmentation was limited to the TGN with the cisand medium-Golgi segments remaining intact [43]. A similarly specific TGN fragmentation was observed for Vero76 cells infected with Rickettsia rickettsii [44]. In Parkinson's disease, the Golgi dispersion was mediated by Rab7L1 GTPase while in the Rickettsia infected cells, dispersion was mediated by RARP2 (Rickettsial Ankyrin Repeat Protein 2) suggesting heterogeneous molecular mechanisms for TGN disruption [43-45]. Moreover, recent studies have demonstrated that the Golgi acts as a platform for the formation of signaling complexes triggering the inflammatory response [46] and that the disassembly of TGN is a crucial event in the activation of the NRPL3 inflammasome. Diverse NRPL3 activators trigger this response, but the cis- and the medial-Golgi remain intact throughout [47]. In the present study, we have shown for the first time that the TGN may also be disrupted in CMT disease or at least in some CMT subtypes caused by mutations within GDAP1. We have revealed this in a series of three independent experiments encompassing neuroblastoma, HeLa and yeast cells. Similarly to the previously reported studies in which selected TGN disruption was observed, the Golgi disturbance we detected in HeLa cells transfected with GDAP1-Leu239Phe was limited to the TGN only. Additionally impaired function of the TGN, at the very least, results in changes to the glycosylation pattern and localization of TGN46. Meanwhile, the localization patterns of cis-, medial- and other TGN proteins (GM130, GORASP2 and B4GALT3, respectively) remain intact, unchanged from the pattern 
observed for control cells. Our finding that the Golgi is affected in CMT sheds new light on the pathology of CMT-GDAP1, which, so far, has only been associated with mitochondrial dysfunction encompassing mitochondrial fission/fusion processes; mitochondrial transport and impaired oxidative phosphorylation [3]. How some GDAP1 gene mutations may selectively affect TGN46, but not B4GALT3 in the TGN of HeLa cells remains unclear. However, there is evidence that the TGN is organized into distinct sub-compartments, marked by specific TGN proteins. Examples of the specific localization of proteins include the distinct localizations of ATP7A, a copper transporting ATPase, and TGN46 [48]. Another example is the localization of golgins: proteins that function as molecular tethers during the docking of transport vesicles to a target membrane during the maintenance of stacked cisternae structures in the Golgi. Two such golgins, GCC88 and GCC185, localize to a common TGN sub-compartment. Alpha-2, 6-sialyltransferase also localizes to this sub-compartment but TGN46 is absent. This sub-compartment is distinct from that which contains p230/golgin-245 and golgin-97 [49]. The mechanism/pathway by which GDAP1 influences the modification and localization of TGN46 remains to be studied. It is also possible that mutations in the DNM2 gene encoding a dynamin and causing CMTIB may affect the structure of the TGN as well as they affect the receptors endocytosis [50]. The same may be true for mutations in the SH3TC2 gene causing CMT4C. These mutations also affect endocytosis, which may reflect a general disturbance of intracellular transport from the TGN and in later stages [51]. To find the molecular mechanism leading to changed TGN46 localization, the molecular partners of GDAP1 need to be identified. From our studies, we predict that the molecular pathway by which GDAP1 influences TGN structure and function is conserved. Similarly to what was observed in HeLa cells, the expression of GDAP1-Leu239Phe in yeast cells changed the distribution of Sec7-mRFP (a TGN marker) while localization of Sed5 (a cis-Golgi marker) remained unchanged. This conservation allows us to use the yeast model to identify the molecular partners of GDAP1 and to uncover the pathways that influence TGN functioning.

The GDAP1 mRNA is one of 10 mRNAs that are highly expressed in the Neuro2a cell line (a mouse neuroblastoma cell line) following neurite-like differentiation. Differentiation is achieved by transfection of these cells with a cDNA encoding the gene for the GD3 synthase [4]. The GD3 synthase is a Golgi membrane protein that catalyzes the formation of GM3 ganglioside, a ceramide-based glycolipid. In yeast, the sphingolipid composition is quite simple: yeast contain three inositol-containing complex sphingolipids only with one mannose. Csg2 influences the mannosylation of inositolphosphorylceramide [52]. Here we present evidence that the effect of GDAP1 expression in a $\operatorname{csg} 2 \triangle$ mutant is most likely not related to its effect on the complex sphingolipid biosynthetic pathway and, by extension, on Golgi structure. Two lines of evidence from our yeast study suggest such a conclusion. Firstly, the addition of myriocin, which inhibits the first enzyme of the sphingolipid biosynthesis pathway, does not abolish the suppression of a $\operatorname{csg} 2 \Delta$ mutant through the expression of GDAP1. Secondly, a comparison of the effect of GDAP1 expression with the known action of chemical suppressors, isolated in a screen, suggests an indirect effect. The identification of cyclosporine $\mathrm{A}$ in the drug screen suggests the involvement of calcium homeostasis. It has been shown that GDAP1-knockouts in either human neuroblastoma SH-SY5Y cells or in mice motor neurons exhibit a defect in store-operated calcium entry (SOCE), a calcium cell-entry pathway $[14,15]$. This phenotype is linked to an observed mislocalization of mitochondria [14]. The selection of ibuprofen as a chemical suppressor mimicking the effect of GDAP1 expression in the $\operatorname{csg} 2 \Delta$ mutant suggests that there may be an additional mechanism. Ibuprofen is the most interesting candidate drug due to the recent findings of Fernandez-Lizarbe et al. regarding neuroinflammation in GDAP1knockout mice [24]. The authors of this elegant study have demonstrated the presence of elevated levels of some proinflammatory mediators (TNF- $\alpha$ and pERK, and the C1qa and C1qb proteins of the complement system) supporting the role of inflammation in the pathogenesis of CMT-GDAP1 disease. Ibuprofen is an anti-inflammatory agent that is able to restore growth of the $\operatorname{csg} 2 \Delta$ mutant yet there are no inflammatory processes 
in yeast cells. This suggests that the initial stages (i.e., biochemical pathways) of the inflammatory process are present in yeast cells. We speculate that this process is related to the maintenance of TGN structure. Regardless of the mechanism of action of ibuprofen, the presence of an inflammatory response in GDAP1-/- mice classify this compound as one of the first potential drugs with which to treat CMT-GDAP1 disease. Given the relatively low number of adverse effects associated with ibuprofen, its use in experimental CMT-GDAP1 therapy is quite realistic.

In conclusion, our work shows that the mitochondrial protein GDAP1 involved in the pathology of CMT is associated with changes in a distinct cell compartment, the TGN. These changes could be responsible for inducing inflammation. Drugs with different mechanisms of action were shown to have activity in the yeast CMT-GDAP1 model. This indicates that multiple molecular pathways can compensate for the lack of GDAP1. Finally, ibuprofen is an encouraging candidate for the treatment of CMT-GDAP1 disease.

\section{Materials and Methods}

\subsection{Yeast Strains, Media and Growth Conditions}

The yeast Saccharomyces cerevisiae strains used in this study were BY4741 MATa his $3 \Delta 1$ leu2 $\Delta 0$ met $15 \Delta 0 u r a 3 \Delta 0$ and BY4741 $\operatorname{csg} 2 \Delta$. Yeast cultures were grown at $28^{\circ} \mathrm{C}$ or at room temperature in YPD medium (1\% yeast extract, $2 \%$ peptone, $2 \%$ glucose) or in complete synthetic medium (SC) $(0.67 \%$ yeast nitrogen base with ammonium sulfate without amino acids, $2 \%$ glucose with complete supplement mixture). For growth tests, the optical cell density $\left(\mathrm{OD}_{600}\right)$ was determined and cultures were diluted with SC-leu medium to $\mathrm{OD}_{600} \approx 1$. Aliquots of 10 -fold serial dilutions of cells were spotted on solid YPD media plates supplemented as indicated. Plates were incubated at room temperature for the number of days indicated.

Neuroblastoma cell line SH-SY5Y (gift from M.Szeliga MMRC PAS) was maintained in DMEM/F12 (Sigma-Aldrich, Saint Louis, MI, USA) containing 10\% FBS (Thermo Fisher Scientific, Waltham, MA, USA), $100 \mathrm{IU} / \mathrm{mL}$ penicillin, and $100 \mu \mathrm{g} / \mathrm{mL}$ streptomycin (Thermo Fisher Scientific), + 1\% Non-Essential Amino Acids (NEAA) (Sigma-Aldrich) and uridine $1 \mathrm{mg} / \mathrm{mL}$ (Sigma-Aldrich). The HeLa cell line from American Type Culture Collection (ATCC, Manassas, VA, USA) was grown in Dulbecco's modified Eagle's medium (DMEM high glucose, GlutaMAX, Thermo Fisher Scientific) containing 10\% FBS (Thermo Fisher Scientific), $100 \mathrm{IU} / \mathrm{mL}$ penicillin, and $100 \mu \mathrm{g} / \mathrm{mL}$ streptomycin (Thermo Fisher Scientific) and uridine $1 \mathrm{mg} / \mathrm{mL}$ (Sigma-Aldrich) in a humidified tissue culture incubator at $37^{\circ} \mathrm{C}$ and $5 \% \mathrm{CO}_{2}$ atmosphere.

For transmission electron microscopy analysis (TEM), SH-SY5Y and HeLa cells were cultured at the seeding density of $1 \times 10^{5}$ cells on Nunc Thermanox Coverslips (ø13 mm, Thermo Fisher Scientific, nr cat.: 174950), placed into 24-well plates and incubated for $24 \mathrm{~h}$ until they reached approximately $70-80 \%$ confluency.

\subsection{Cell Transfection and GDAP1 Silencing}

HeLa and SH-SY5Y cells were transfected using the pIRES2-AcGFP1 Vector with Viromer Red (Lipocalyx, Halle, Germany) according to the manufacturer's recommendations with the standard transfection scale. In all cases, the medium was changed $48 \mathrm{~h}$ after transfection. The resulting transfectant HeLa and SH-SY5Y cells were cultured in an appropriate medium with $500 \mu \mathrm{g} / \mathrm{mL}$ G418 (Lab Empire, Rzeszów, Poland) for 2 weeks.

For the generation of a GDAP1-silenced SH-SY5Y cell line, cells were seeded on 24well plate to a confluency of about $70-80 \%$ and transfected using $1.6 \mu \mathrm{L}$ of siRNA (10 $\mu \mathrm{M}$ solution) (Qiagen, Valencia, CA, USA) per well and Lipofectamine 3000 (Thermo Fisher Scientific) as recommended by the manufacturer. Clonal cell lines were tested for GDAP1 silencing by Western blot.

\subsection{Plasmids and DNA Manipulations}

The plasmids used in this study are listed in Table 1. 
Table 1. Plasmids used in this study.

\begin{tabular}{|c|c|c|}
\hline Name & Description & Source \\
\hline \multicolumn{3}{|c|}{ Yeast Plasmids: } \\
\hline $\mathrm{p} 425-\mathrm{P}_{\mathrm{TDH} 3}$ & $2 \mu ; L E U 2$ & [53] \\
\hline $\mathrm{p} 425-\mathrm{P}_{\mathrm{TDH} 3}-\mathrm{GDAP1}$ & $2 \mu ; L E U 2 ; G D A P 1$ & [16] \\
\hline $\mathrm{p} 425-\mathrm{P}_{\mathrm{TDH}}-G D A P 1 m 2$ & $\begin{array}{c}2 \mu ; \text { LEU2; GDAP1 c. } 980 \mathrm{G}>\mathrm{A} ; \\
\text { p.Gly327Asp }\end{array}$ & [16] \\
\hline $\mathrm{p} 425-\mathrm{P}_{\mathrm{TDH}}-G D A P 1 m 5$ & $\begin{array}{l}2 \mu ; \text { LEU2; GDAP1 c.715C > T; } \\
\text { p.Leu239Phe }\end{array}$ & [16] \\
\hline Sec7-mRFP & URA3; SEC7-mRFP & {$[31]$} \\
\hline Sed5-mRFP & URA3; SED5-mRFP & [31] \\
\hline \multicolumn{3}{|c|}{ Mammalian Expression Plasmids: } \\
\hline pCMV6-XL5-GDAP1 & Human Untagged Clone GDAP1 cDNA & OriGene \\
\hline pCMV6-XL5-GDAP1m1 & GDAP1 c.456delC; p.Pro153Argfs*19 & This study \\
\hline pCMV6-XL5-GDAP1m2 & GDAP1 c.980G > A; p.Gly327Asp & This study \\
\hline pCMV6-XL5-GDAP1m3 & GDAP1 c.652C > G; p.Gln218Glu & This study \\
\hline pCMV6-XL5-GDAP1m4 & GDAP1 c.664G > A; p.Glu222Lys & This study \\
\hline pCMV6-XL5-GDAP1m5 & GDAP1 c.715C > T; p.Leu239Phe & This study \\
\hline pCMV6-XL5-GDAP1m6 & GDAP1 c.368A > G; p.His123Arg & This study \\
\hline pIRES2-AcGFP1 & Bicistronic vector with GFP & TAKARA Bio \\
\hline pIRES2-AcGFP1-GDAP1 & GDAP1 WT & This study \\
\hline pIRES2-AcGFP1-GDAP1m1 & GDAP1 c.456delC; p.Pro153Argfs*19 & This study \\
\hline pIRES2-AcGFP1-GDAP1m2 & GDAP1 c.980G > A; p.Gly327Asp & This study \\
\hline pIRES2-AcGFP1-GDAP1m3 & GDAP1 c.652C > G; p.Gln218Glu & This study \\
\hline pIRES2-AcGFP1-GDAP1m4 & GDAP1 c.664G > A; p.Glu222Lys & This study \\
\hline pIRES2-AcGFP1-GDAP1m5 & GDAP1 c.715C > T; p.Leu239Phe & This study \\
\hline pIRES2-AcGFP1-GDAP1m6 & GDAP1 c.368A > G; p.His123Arg & This study \\
\hline
\end{tabular}

GDAP1 cDNA was subcloned from pCMV6-XL5 GDAP1 (NM_018972) Human Untagged Clone (OriGene Technologies Inc., Rockville, MD, USA) to pIRES2-AcGFP1 Vector (TAKARA Bio, Shiga, Japan) using SacI and Sall enzymes (Thermo Fisher Scientific).

Mutagenesis for mutations in the GDAP1 gene (c.980G > A p.Gly327Asp, c.458C > T p.Pro153Leu, c.652C > G p.Gln218Glu, c.664G > A p.Glu222Lys, c.715C > T p.Leu239Phe and c.368A > G p.His123Arg) were performed using Mut Express II Fast Mutagenesis Kit V2 (Vazyme Biotech Co., Ltd., Nanjing, Jiangsu, China) according to the manufacturer's instructions and verified by sequencing.

\subsection{Protein Extracts and Western Blot Analysis}

Total protein cell extracts were prepared using a cell lysis buffer (Cell Signaling Technology, Inc., Danvers, MA, USA) with $1 \mathrm{mM}$ PMSF and Protease Inhibitor Cocktail 1/200 $v / v$ (Sigma-Aldrich). Protein were separated by SDS-PAGE, transferred onto nitrocellulose membrane Amersham Protran (GE Healthcare Bio-Sciences AB, Uppsala, Sweden) and analyzed by standard Western blotting using rabbit polyclonal anti-GDAP1 (Abcam, Cambridge, MA, USA), purified mouse anti-GM130 (BD Transduction Laboratories, San Jose, CA, USA), rabbit polyclonal anti-B4GALT3 (Proteintech, Chicago, IL, USA), rabbit polyclonal anti-GORASP2 (Proteintech), rabbit anti-TGN46 (Sigma-Aldrich), mouse monoclonal anti-beta Actin (Proteintech) antibodies and secondary anti-rabbit IgG and anti-mouse 
IgG horseradish peroxidase (HRP)-conjugated antibodies (Sigma-Aldrich) followed by enhanced chemiluminescence (Western Bright Sirius Advansta, San Jose, CA, USA).

\subsection{Drug Screening Assay}

The assay was based on previously described tests [33,34]. Cells of the yeast $S$. cerevisiae strain $\operatorname{csg} 2 \Delta$ were grown to early exponential phase, $\mathrm{OD}_{600}$ was adjusted to 0.5 , and $200 \mu \mathrm{L}$ was spread homogenously onto solid YPD media supplemented with $0.5 \mathrm{M} \mathrm{CaCl}_{2}$. Sterile filters were placed on the media surface and $5 \mu \mathrm{L}$ of $10 \mathrm{mM}$ drug solutions in dimethyl sulfoxide (DMSO) were applied to each filter disc. In this screen, all 1520 compounds from the Prestwick Chemical Library (Prestwick Chemical Libraries, Illkirch-Graffenstaden, France), 99\% of which have been approved by Food and Drug Administration, USA, were tested. DMSO was used as a vehicle control. As a positive control the $\operatorname{csg} 2 \Delta$ strain with plasmid encoding human GDAP1 gene $(\operatorname{csg} 2 \triangle$ [GDAP1]) was used. The $\operatorname{csg} 2 \triangle$ [GDAP1] strain was spotted directly on the surface of the media in the corner of each plate. The plates were incubated at $28^{\circ} \mathrm{C}$ for 3 to 5 days. Data was recorded using a Snap Scan 1212 (Agfa, Mortsel, Belgium).

\subsection{Confocal Microscopy}

HeLa and SH-SY5Y cells were grown on $12 \mathrm{~mm}$ poly-L-lysine-coated coverslips. Cells were fixed by incubation for $15 \mathrm{~min}$ in $4 \%$ formaldehyde in PBS followed by $10 \mathrm{~min}$ of permeabilization in $0.5 \%$ Triton-X in PBS and then blocked for $1 \mathrm{~h}$ in $0.1 \%$ Triton-X and $2 \%$ BSA in PBS. The slides were incubated overnight with primary antibody: purified mouse anti-GM130 diluted 1:40 (BD Transduction Laboratories), rabbit polyclonal anti-B4GALT3 diluted 1:65 (Proteintech), rabbit polyclonal anti-GORASP2 diluted 1:300 (Proteintech), rabbit anti-TGN46 diluted 1:200 (Sigma-Aldrich). After washing, slides were incubated with secondary antibody Alexa Fluor 546-conjugated goat anti-rabbit or anti-mouse IgG (Invitrogen, Camarillo, CA, USA) diluted 1:500 for $1 \mathrm{~h}$. Then slides were stained using DAPI (Thermo Fisher Scientific) for $15 \mathrm{~min}$ and mounted in mounting medium (DAKO, Agilent, Santa Clara, CA, USA).

To observe the morphology of Golgi in yeast cells, BY4741 strains carrying a SEC7$m R F P$ - or SED5-mRFP- containing plasmid were transformed with empty plasmid or plasmids bearing the indicated GDAP1 variants. Strains were grown overnight in SC-leuura media at $28^{\circ} \mathrm{C}$. Cultures were diluted (1:10) in fresh SC-leu-ura medium for $4 \mathrm{~h}$. Cells were collected by centrifugation, fixed by incubation for $25 \mathrm{~min}$ in $4 \%$ formaldehyde and washed in KiPO4/sorbitol buffer (100 mM potassium phosphate $\mathrm{pH} 7.5$ and $1.2 \mathrm{M}$ sorbitol). Fixed cultures were spotted on poly-L-lysine- or concanavalin A-coated slides and the nucleus was stained by DAPI (Thermo Fisher Scientific) for $2 \mathrm{~min}$. Slides were then washed with water and mounted in a mounting medium (DAKO).

Cells were viewed using LSM 780 Axio Observer Z.1 confocal microscope (Zeiss, Oberkochen, Germany). Images were collected using Zen 2012 black edition software (Zeiss). The confocal microscopy observations were performed in the Laboratory of Advanced Microscopy Techniques, Mossakowski Medical Research Centre, PAS. At least 100 yeast cells with Sec7-mRFP and Sed5-mRFP were counted for every experimental variant.

\subsection{Transmission Electron Microscopy}

Cells were fixed by $2.5 \%$ glutaraldehyde, $2 \%$ paraformaldehyde (Electron Microscopy Sciences, Hatfield, PA, USA) solution for $1 \mathrm{~h}$ at $4^{\circ} \mathrm{C}$. After fixation, cells were rinsed three times for $10 \mathrm{~min}$ in $0.1 \mathrm{M}$ cacodylate buffer (BDH Chemicals, Dubai, UAE). Cells were then postfixed in 2\% osmium tetroxide (Agar Scientific, Stansted, United Kingdom) for $1 \mathrm{~h}$ at room temperature. Dehydration was performed by incubating the sample in increasing ethanol concentrations and then in pure propylene oxide. During dehydration, cells were stained with 1\% uranyl acetate (Serva, Heidelberg, Germany) in $70 \%$ ethanol. Finally, cells were embedded in a mixture of propylene oxide (Electron Microscopy Sciences) and Epon resin (Serva), then in pure Epon resin. After polymerization at $60^{\circ} \mathrm{C}, 70 \mathrm{~nm}$ 
thick sections were collected on TEM copper grids (Ted Pella Inc., Redding, CA, USA). Electron micrographs were obtained with Morada camera on a JEM 1400 transmission electron microscope at $80 \mathrm{kV}$ (JEOL Co., Tokyo, Japan) in the Laboratory of Electron Microscopy Core Facility, Nencki Institute of Experimental Biology, Polish Academy of Sciences, Warsaw, Poland.

\subsection{Statistical Analysis}

Statistical analyses were performed using GraphPad Prism Software (San Diego, CA, USA) (https://www.graphpad.com/scientific-software/prism/). Student's $t$-Test was used to evaluate the statistical significance of differences between the numbers of Sec7mRFP puncta in transformed yeast cells. One-way ANOVA was used to evaluate the statistical significance of differences between the fractions of cells with the indicated types of Golgi ultrastructure. Data are presented as means \pm standard deviations. The differences are considered significant where $p<0.05$.

Supplementary Materials: The following are available online at https:/ /www.mdpi.com/1422-006 7/22/2/914/s1, Figure S1: Expression of the GDAP1 gene variants in yeast cells does not change the localization of the cis-Golgi protein Sed5.

Author Contributions: Conceptualization: J.K., A.K., D.K. (Dagmara Kabzińska); resources: A.K.; writing—original draft preparation: J.K., D.K. (Dagmara Kabzińska), W.R., K.B., A.K.; supervision: J.K., D.K. (Dagmara Kabzińska); funding acquisition: A.K., K.B.; formal analysis: W.R., K.B., A.A.S., H.N.; investigation: W.R., D.K. (Dagmara Kabzińska), K.B., D.K. (Damian Kolakowski), A.A.S., H.N.; methodology: J.K., W.R., project administration: D.K. (Dagmara Kabzińska); validation: J.K., D.K. (Dagmara Kabzińska), W.R.; visualization: W.R., D.K. (Dagmara Kabzińska), K.B., A.A.S., H.N.; writing—review and editing: W.R., J.K., D.K. (Dagmara Kabzińska), K.B., A.K.; All authors have read and agreed to the published version of the manuscript.

Funding: This research was funded by National Science Centre Poland, grant number UMO2016/23/B/NZ3/02035 to A.K. and by European Social Fund, POWR.03.02.00-00-1028/17-00 to K.B.

Institutional Review Board Statement: Not applicable.

Informed Consent Statement: Not applicable.

Data Availability Statement: The data presented in this study are available on request from the corresponding author. The data are not publicly available due to privacy.

Acknowledgments: We would like to thank Monika Szeliga for providing the SH-SY5Y cell line.

Conflicts of Interest: The authors declare no conflict of interest.

\section{References}

1. Sevilla, T.; Jaijo, T.; Nauffal, D.; Collado, D.; Chumillas, M.J.; Vilchez, J.J.; Muelas, N.; Bataller, L.; Domenech, R.; Espinós, C.; et al. Vocal cord paresis and diaphragmatic dysfunction are severe and frequent symptoms of GDAP1-associated neuropathy. Brain 2008, 131, 3051-3061. [CrossRef]

2. Kabzińska, D.; Niemann, A.; Drac, H.; Huber, N.; Potulska-Chromik, A.; Hausmanowa-Petrusewicz, I.; Suter, U.; Kochański, A. A new missense GDAP1 mutation disturbing targeting to the mitochondrial membrane causes a severe form of AR-CMT2C disease. Neurogenetics 2011, 12, 145-153. [CrossRef]

3. Rzepnikowska, W.; Kochański, A. A role for the GDAP1 gene in the molecular pathogenesis of Charcot-Marie-Tooth disease. Acta Neurobiol. Exp. 2018, 78, 1-13. [CrossRef]

4. Liu, H.; Nakagawa, T.; Kanematsu, T.; Uchida, T.; Tsuji, S. Isolation of 10 differentially expressed cDNAs in differentiated Neuro2a cells induced through controlled expression of the GD3 synthase gene. J. Neurochem. 1999, 72, 1781-1790. [CrossRef] [PubMed]

5. Baxter, R.V.; Othmane, K.B.; Rochelle, J.M.; Stajich, J.E.; Hulette, C.; Dew-Knight, S.; Hentati, F.; Hamida, M.B.; Bel, S.; Stenger, J.E.; et al. Ganglioside-induced differentiation-associated protein-1 is mutant in Charcot-Marie-Tooth disease type 4A/8q21. Nat. Genet. 2002, 30, 21-22. [CrossRef] [PubMed]

6. Cuesta, A.; Pedrola, L.; Sevilla, T.; García-Planells, J.; Chumillas, M.J.; Mayordomo, F.; LeGuern, E.; Marín, I.; Vílchez, J.J.; Palau, F. The gene encoding ganglioside-induced differentiation-associated protein 1 is mutated in axonal Charcot-Marie-Tooth type 4A disease. Nat. Genet. 2002, 30, 22-25. [CrossRef] [PubMed] 
7. González-Sánchez, P.; Satrústegui, J.; Palau, F.; Del Arco, A. Calcium deregulation and mitochondrial bioenergetics in GDAP1related CMT disease. Int. J. Mol. Sci. 2019, 20, 403. [CrossRef] [PubMed]

8. Niemann, A.; Ruegg, M.; La Padula, V.; Schenone, A.; Suter, U. Ganglioside-induced differentiation associated protein 1 is a regulator of the mitochondrial network: New implications for Charcot-Marie-Tooth disease. J. Cell Biol. 2005, 170, 1067-1078. [CrossRef] [PubMed]

9. Pedrola, L.; Espert, A.; Wu, X.; Claramunt, R.; Shy, M.E.; Palau, F. GDAP1, the protein causing Charcot-Marie-Tooth disease type 4A, is expressed in neurons and is associated with mitochondria. Hum. Mol. Genet. 2005, 14, 1087-1094. [CrossRef]

10. Marco, A.; Cuesta, A.; Pedrola, L.; Palau, F.; Marín, I. Evolutionary and Structural Analyses of GDAP1, Involved in CharcotMarie-Tooth Disease, Characterize a Novel Class of Glutathione Transferase-Related Genes. Mol. Biol. Evol. 2004, 21 , 176-187. [CrossRef]

11. Shield, A.J.; Murray, T.P.; Board, P.G. Functional characterisation of ganglioside-induced differentiation-associated protein 1 as a glutathione transferase. Biochem. Biophys. Res. Commun. 2006, 347, 859-866. [CrossRef] [PubMed]

12. Googins, M.R.; Woghiren-Afegbua, A.O.; Calderon, M.; St. Croix, C.M.; Kiselyov, K.I.; VanDemark, A.P. Structural and functional divergence of GDAP1 from the glutathione S-transferase superfamily. FASEB J. 2020, 34, 7192-7207. [CrossRef]

13. Pla-Martín, D.; Calpena, E.; Lupo, V.; Márquez, C.; Rivas, E.; Sivera, R.; Sevilla, T.; Palau, F.; Espinós, C. Junctophilin-1 is a modifier gene of GDAP1-related Charcot-Marie-Tooth disease. Hum. Mol. Genet. 2015, 24, 213-229. [CrossRef] [PubMed]

14. Pla-Martín, D.; Rueda, C.B.; Estela, A.; Sánchez-Piris, M.; González-Sánchez, P.; Traba, J.; de la Fuente, S.; Scorrano, L.; Renau-Piqueras, J.; Alvarez, J.; et al. Silencing of the Charcot-Marie-Tooth disease-associated gene GDAP1 induces abnormal mitochondrial distribution and affects Ca2+ homeostasis by reducing store-operated Ca2+ entry. Neurobiol. Dis. 2013, 55, 140-151. [CrossRef] [PubMed]

15. Barneo-Muñoz, M.; Juárez, P.; Civera-Tregón, A.; Yndriago, L.; Pla-Martin, D.; Zenker, J.; Cuevas-Martín, C.; Estela, A.; SánchezAragó, M.; Forteza-Vila, J.; et al. Lack of GDAP1 Induces Neuronal Calcium and Mitochondrial Defects in a Knockout Mouse Model of Charcot-Marie-Tooth Neuropathy. PLoS Genet. 2015, 11, 1-27. [CrossRef]

16. Rzepnikowska, W.; Kaminska, J.; Kabzińska, D.; Kochański, A. Pathogenic effect of GDAP1 gene mutations in a yeast model. Genes 2020, 11, 310. [CrossRef]

17. Huber, N.; Guimaraes, S.; Schrader, M.; Suter, U.; Niemann, A. Charcot-Marie-Tooth disease-associated mutants of GDAP1 dissociate its roles in peroxisomal and mitochondrial fission. EMBO Rep. 2013, 14, 545-552. [CrossRef]

18. Niemann, A.; Wagner, K.M.; Ruegg, M.; Suter, U. GDAP1 mutations differ in their effects on mitochondrial dynamics and apoptosis depending on the mode of inheritance. Neurobiol. Dis. 2009, 36, 509-520. [CrossRef]

19. Cassereau, J.; Chevrollier, A.; Gueguen, N.; Malinge, M.C.; Letournel, F.; Nicolas, G.; Richard, L.; Ferre, M.; Verny, C.; Dubas, F.; et al. Mitochondrial complex i deficiency in GDAP1-related autosomal dominant Charcot-Marie-Tooth disease (CMT2K). Neurogenetics 2009, 10, 145-150. [CrossRef]

20. Noack, R.; Frede, S.; Albrecht, P.; Henke, N.; Pfeiffer, A.; Knoll, K.; Dehmel, T.; zu Hörste, G.M.; Stettner, M.; Kieseier, B.C.; et al. Charcot-Marie-Tooth disease CMT4A: GDAP1 increases cellular glutathione and the mitochondrial membrane potential. Hum. Mol. Genet. 2012, 21, 150-162. [CrossRef]

21. García-Sobrino, T.; Blanco-Arias, P.; Palau, F.; Espinós, C.; Ramirez, L.; Estela, A.; Millán, B.S.; Arias, M.; Sobrido, M.J.; Pardo, J. Phenotypical features of a new dominant GDAP1 pathogenic variant (p.R226del) in axonal Charcot-Marie-Tooth disease. Neuromuscul. Disord. 2017, 27, 667-672. [CrossRef] [PubMed]

22. González-Sánchez, P.; Pla-Martín, D.; Martínez-Valero, P.; Rueda, C.B.; Calpena, E.; Del Arco, A.; Palau, F.; Satrústegui, J. CMT-linked loss-of-function mutations in GDAP1 impair store-operated Ca 2+ entry-stimulated respiration. Sci. Rep. 2017, 7, 1-12. [CrossRef] [PubMed]

23. Cassereau, J.; Chevrollier, A.; Codron, P.; Goizet, C.; Gueguen, N.; Verny, C.; Reynier, P.; Bonneau, D.; Lenaers, G.; Procaccio, V. Oxidative stress contributes differentially to the pathophysiology of Charcot-Marie-Tooth disease type 2K. Exp. Neurol. 2020, 323, 113069. [CrossRef] [PubMed]

24. Fernandez-Lizarbe, S.; Civera-Tregón, A.; Cantarero, L.; Herrer, I.; Juarez, P.; Hoenicka, J.; Palau, F. Neuroinflammation in the pathogenesis of axonal Charcot-Marie-Tooth disease caused by lack of GDAP1. Exp. Neurol. 2019, 320, 113004. [CrossRef]

25. Wei, J.H.; Seemann, J. Unraveling the Golgi ribbon. Traffic 2010, 11, 1391-1400. [CrossRef]

26. Li, J.; Ahat, E.; Wang, Y. Golgi Structure and Function in Health, Stress, and Diseases. In Results and Problems in Cell Differentiation; Springer: Berlin/Heidelberg, Germany, 2019; Volume 67, pp. 441-485.

27. Martínez-Menárguez, J.A. Intra-Golgi Transport: Roles for Vesicles, Tubules, and Cisternae. ISRN Cell Biol. 2013, 2013 , 1-15. [CrossRef]

28. Pedrola, L.; Espert, A.; Valdés-Sánchez, T.; Sánchez-Piris, M.; Sirkowski, E.E.; Scherer, S.S.; Fariñas, I.; Palau, F. Cell expression of GDAP1 in the nervous system and pathogenesis of Charcot-Marie-Tooth type 4A disease. J. Cell. Mol. Med. 2008, 12, 679-689. [CrossRef]

29. Zimoń, M.; Baets, J.; Fabrizi, G.M.; Jaakkola, E.; Kabzińska, D.; Pilch, J.; Schindler, A.B.; Cornblath, D.R.; Fischbeck, K.H.; Auer-Grumbach, M.; et al. Dominant GDAP1 mutations cause predominantly mild CMT phenotypes. Neurology 2011, 77, 540-548. [CrossRef] 
30. Kabzińska, D.; Strugalska-Cynowska, H.; Kostera-Pruszczyk, A.; Ryniewicz, B.; Posmyk, R.; Midro, A.; Seeman, P.; Baránková, L.; Zimon, M.; Baets, J.; et al. L239F founder mutation in GDAP1 is associated with a mild Charcot-Marie-Tooth type 4C4 (CMT4C4) phenotype. Neurogenetics 2010, 11, 357-366. [CrossRef]

31. Matsuura-Tokita, K.; Takeuchi, M.; Ichihara, A.; Mikuriya, K.; Nakano, A. Live imaging of yeast Golgi cisternal maturation. Nature 2006, 441, 1007-1010. [CrossRef]

32. Wood, C.S.; Hung, C.S.; Huoh, Y.S.; Mousley, C.J.; Stefan, C.J.; Bankaitis, V.; Ferguson, K.M.; Burd, C.G. Local control of phosphatidylinositol 4-phosphate signaling in the Golgi apparatus by Vps74 and Sac1 phosphoinositide phosphatase. Mol. Biol. Cell 2012, 23, 2527-2536. [CrossRef] [PubMed]

33. Bach, S.; Talarek, N.; Andrieu, T.; Vierfond, J.M.; Mettey, Y.; Galons, H.; Dormont, D.; Meijer, L.; Cullin, C.; Blondel, M. Isolation of drugs active against mammalian prions using a yeast-based screening assay. Nat. Biotechnol. 2003, 21, 1075-1081. [CrossRef] [PubMed]

34. Couplan, E.; Aiyar, R.S.; Kucharczyk, R.; Kabala, A.; Ezkurdia, N.; Gagneur, J.; Onge, R.P.S.; Salin, B.; Soubigou, F.; Le Cann, M.; et al. A yeast-based assay identifies drugs active against human mitochondrial disorders. Proc. Natl. Acad. Sci. USA 2011, 108, 11989-11994. [CrossRef] [PubMed]

35. Soczewka, P.; Flis, K.; Tribouillard-Tanvier, D.; Di Rago, J.P.; Santos, C.N.; Menezes, R.; Kaminska, J.; Żołądek, T. Flavonoids as potential drugs for VPS13-dependent rare neurodegenerative diseases. Genes 2020, 11, 828. [CrossRef]

36. Passage, E.; Norreel, J.C.; Noack-Fraissignes, P.; Sanguedolce, V.; Pizant, J.; Thirion, X.; Robaglia-Schlupp, A.; Pellissier, J.F.; Fontés, M. Ascorbic acid treatment corrects the phenotype of a mouse model of Charcot-Marie-Tooth disease. Nat. Med. 2004, 10, 396-401. [CrossRef]

37. Zu Horste, G.M.; Prukop, T.; Liebetanz, D.; Mobius, W.; Nave, K.A.; Sereda, M.W. Antiprogesterone therapy uncouples axonal loss from demyelination in a transgenic rat model of CMT1A neuropathy. Ann. Neurol. 2007, 61, 61-72. [CrossRef]

38. Cottenie, E.; Kochanski, A.; Jordanova, A.; Bansagi, B.; Zimon, M.; Horga, A.; Jaunmuktane, Z.; Saveri, P.; Rasic, V.M.; Baets, J.; et al. Truncating and missense mutations in IGHMBP2 cause Charcot-Marie Tooth disease type 2. Am. J. Hum. Genet. 2014, 95, 590-601. [CrossRef]

39. Fourriere, L.; Jimenez, A.J.; Perez, F.; Boncompain, G. The role of microtubules in secretory protein transport. J. Cell Sci. 2020, 133, jcs237016. [CrossRef]

40. Brunden, K.R.; Lee, V.M.-Y.; Smith, A.B.; Trojanowski, J.Q.; Ballatore, C. Altered microtubule dynamics in neurodegenerative disease: Therapeutic potential of microtubule-stabilizing drugs. Neurobiol. Dis. 2017, 105, 328-335. [CrossRef]

41. Sancho, P.; Bartesaghi, L.; Miossec, O.; García-García, F.; Ramírez-Jiménez, L.; Siddell, A.; Åkesson, E.; Hedlund, E.; Laššuthová, P.; Pascual-Pascual, S.I.; et al. Characterization of molecular mechanisms underlying the axonal Charcot-Marie-Tooth neuropathy caused by MORC2 mutations. Hum. Mol. Genet. 2019, 28, 1629-1644. [CrossRef]

42. Martínez-Menárguez, J.Á.; Tomás, M.; Martínez-Martínez, N.; Martínez-Alonso, E. Golgi Fragmentation in Neurodegenerative Diseases: Is There a Common Cause? Cells 2019, 8, 748. [CrossRef] [PubMed]

43. Fujimoto, T.; Kuwahara, T.; Eguchi, T.; Sakurai, M.; Komori, T.; Iwatsubo, T. Parkinson's disease-associated mutant LRRK2 phosphorylates Rab7L1 and modifies trans-Golgi morphology. Biochem. Biophys. Res. Commun. 2018, 495, 1708-1715. [CrossRef] [PubMed]

44. Aistleitner, K.; Clark, T.; Dooley, C.; Hackstadt, T. Selective fragmentation of the trans-Golgi apparatus by Rickettsia rickettsii. PLoS Pathog. 2020, 16, 1-22. [CrossRef] [PubMed]

45. Wang, S.; Ma, Z.; Xu, X.; Wang, Z.; Sun, L.; Zhou, Y.; Lin, X.; Hong, W.; Wang, T. A Role of Rab29 in the Integrity of the Trans-Golgi Network and Retrograde Trafficking of Mannose-6-Phosphate Receptor. PLoS ONE 2014, 9, e96242. [CrossRef] [PubMed]

46. Tao, Y.; Yang, Y.; Zhou, R.; Gong, T. Golgi Apparatus: An Emerging Platform for Innate Immunity. Trends Cell Biol. 2020, 30, 467-477. [CrossRef] [PubMed]

47. Chen, J.; Chen, Z.J. PtdIns4P on dispersed trans-Golgi network mediates NLRP3 inflammasome activation. Nature 2018, 564, 71-76. [CrossRef] [PubMed]

48. Holloway, Z.G.; Grabski, R.; Szul, T.; Styers, M.L.; Coventry, J.A.; Monaco, A.P.; Sztul, E. Activation of ADP-ribosylation factor regulates biogenesis of the ATP7A-containing trans-Golgi network compartment and its Cu-induced trafficking. Am. J. Physiol. Cell Physiol. 2007, 293, C1753-C1767. [CrossRef]

49. Gleeson, P.A.; Lock, J.G.; Luke, M.R.; Stow, J.L. Domains of the TGN: Coats, tethers and G proteins. Traffic 2004, 5, 315-326. [CrossRef]

50. Bitoun, M.; Durieux, A.; Prudhon, B.; Bevilacqua, J.A.; Herledan, A.; Sakanyan, V.; Urtizberea, A.; Cartier, L.; Romero, N.B.; Guicheney, P. Dynamin 2 mutations associated with human diseases impair clathrin-mediated receptor endocytosis. Hum. Mutat. 2009, 30, 1419-1427. [CrossRef]

51. Gouttenoire, E.A.; Lupo, V.; Calpena, E.; Bartesaghi, L.; Schüpfer, F.; Médard, J.J.; Maurer, F.; Beckmann, J.S.; Senderek, J.; Palau, F.; et al. Sh3tc2 deficiency affects neuregulin-1/ErbB signaling. Glia 2013, 61, 1041-1051. [CrossRef]

52. Uemura, S.; Kihara, A.; Iwaki, S.; Inokuchi, J.-I.; Igarashi, Y. Regulation of the transport and protein levels of the inositol phosphorylceramide mannosyltransferases Csg1 and Csh1 by the Ca2+-binding protein Csg2. J. Biol. Chem. 2007, 282, 8613-8621. [CrossRef] [PubMed]

53. Mumberg, D.; Müller, R.; Funk, M. Yeast vectors for the controlled expression of heterologous proteins in different genetic backgrounds. Gene 1995, 156, 119-122. [CrossRef] 